\title{
Quality of Sleep and Academic Performance among Medical University Students
}

\author{
Rbiya Javaid ${ }^{1}$, Ain ul Momina ${ }^{2}$, Muhammad Zeeshan Sarwar ${ }^{3}$ and Syed Asghar Naqi ${ }^{3}$ \\ ${ }^{1}$ Gynae Operation Theatre, DHQ Hospital, Kasur, Pakistan \\ ${ }^{2}$ Department of Community Medicine, King Edward Medical University, Lahore, Pakistan \\ ${ }^{3}$ Department of East Surgical Ward, King Edward Medical University, Lahore, Pakistan
}

\begin{abstract}
Objective: To assess the effect of sleep quality on academic performance of medical university students.

Study Design: Descriptive study.

Place and Duration of Study: King Edward Medical University, Lahore, from December 2017 to April 2018.

Methodology: Second to final year Medical and Allied Health Sciences students filled out questionnaires that comprised of three major components. With the help of questionnaire, demographic data about the subjects along with academic scores were collected. Pittsburgh Sleep Quality Index (PSQI) and Epworth Sleeping Scale (ESS) were used to collect the data. Qualitative variables are represented as frequencies and percentages; while, quantitative variables are reported as mean along with standard deviation \pm S.D. Chi-square and was applied for statistical significance, and $p$-value $<0.05$ was considered.

Results: A total of 810 students, including both MBBS and Allied Health Sciences (AHS), filled out the questionnaire. Among those, $564(69.6 \%)$ were females and $246(30.4 \%)$ were males. Overall, mean age was $21.35 \pm 1.51$ years. Of the total, 418 (51.6\%) were from MBBS programme and $392(48.4 \%)$ were from AHS. No significant relationship was found between PSQI and academic scores. However, academic scores had a strong association with ESS scores.

Conclusion: Although the majority of the studied students had poor sleep; but its effect on academic scores was not significant.
\end{abstract}

Key Words: Sleep quality, Medical students, Academic performance.

How to cite this article: Javaid R, Momina AU, Sarwar MZ, Naqi SA. Quality of Sleep and Academic Performance among Medical University Students. J Coll Physicians Surg Pak 2020; 30(08):844-848.

\section{INTRODUCTION}

One of the most important components for a healthy life and a better functioning body is adequate, balanced sleep. Average sleep duration in an adult ranges from 7 to 8 hours with a biphasic pattern recommended as the healthiest. ${ }^{1-3}$ Sleep disturbances are endemic in modern world; approximately one-third of adults report some form of insomnia. ${ }^{4,5}$ Poor sleep quality may lead to excessive daytime sleepiness (EDS) defined as sudden, uncontrollable compulsion to fall asleep during daytime. ${ }^{1}$

Medical students constitute a particularly more vulnerable population than non-medical students and general population. This is the result of various factors that induce stress, some of them include excessive academic burden, crammed schedules, prolonged study sessions, examination stress, peer pressure, high parental expectations and extremely competitive environment. $^{6}$

Correspondence to: Dr. Rbiya Javaid, Gynae Operation

Theater, DHQ Hospital, Kasur, Pakistan

E-mail: rbiyajavaid555@gmail.com

Received: February 06, 2020; Revised: February 10, 2020;

Accepted: August 10, 2020

DOI: https://doi.org/10.29271/jcpsp.2020.08.844
Sleep disturbance among medical students not only subjects them to psychiatric illnesses, but also adversely impacts their cognitive skills, emotional intelligence, and academic performance. ${ }^{7,8}$ This will ultimately alter their work performance in the long run as practitioners that can have significant impact on healthcare as service providers in the healthcare system. ${ }^{9}$ Buboltz et al. reported that on an average, $15 \%$ of college students were unsatisfied with their quality of sleep. ${ }^{8}$ Another study reported that as much as $38.9 \%$ students had a poor sleep quality as indicated by their PSQI scores, which was affecting their academic learning. ${ }^{10}$

Several studies have reported the poor sleep quality among medical students in Pakistani medical schools. However, this paper will contribute to exiting literature by using tools (PSQI) that have been not explored previously. ${ }^{1,2,11}$ The study will try to look if any relation can be established between the scores obtained from these scales and their association with academics. The study was conducted to determine the sleep quality by using PSQI among medical students and also explore the relationship between academic performances, EDS and sleep quality among medical students.

\section{METHODOLOGY}

The cross sectional study took place at King Edward Medical 
University from December 2017 to April 2018. A convenience sample of students from Second to Final year students was drawn. First year students were not included in the study since they have not gone through any professional examination; therefore, they had no academic scores as of yet. Students, who were using sedative medications and/or narcotics for any acute or chronic medical condition, were also not included in the study. Inaddition, students who declined theinvitation to participate in the study, whose responses were not complete for the entire questionnaire or who did not record their grades, were also not included. The study protocol was designed in accordance with the ethical guidelines of the 1961 Declaration of Helsinki and approved by the Institutional Review Board of King Edward Medical University (KEMU), Lahore.

An orientation meeting was arranged with the potential participants on the first day at the University after they had completed their examination. They were briefed about the research objectives and were given instructions on how to fill the questionnaire. Participants were asked to record the time when they wake up and go to sleep for four consecutive weeks. Participation was voluntary and unpaid. Out of 850 , a total of 810 students (418 MBBS and 392 AHS) completed the questionnaire and were followedup until declaration of examination results and subsequent academic scores were recorded.

Scores in form of percentages from the last professional examination were used as a measure of academic performance. Depending upon these scores, students were categorised into five group (<60\%, 60-70\%, 70-80\%, 80-90\% and $>90 \%$ ). They were asked to fill in a self-administered questionnaire that was developed after a thorough literature review. The questionnaire was designed in English, and divided into three main components.

The first component comprised of the variables that would help in collecting demographic information about the student such as age, gender, years of education in addition to sleep and study pattern.

The second component was Pittsburgh Sleep Quality Index (PSQI) that will capture quality of sleep. This self-administered questionnaire assesses the quality of sleep during past four weeks and contains 19 self-rated questions that yields seven components: subjective sleep quality sleep, latency, sleep duration, sleep efficiency and sleep disturbance and daytime dysfunction. Each component is to be assigned a scored that ranges from zero to three, yielding a PSQI score in a range that goes from 0 to 21 . A total score of 0 to 4 is considered as normal sleep quality; whereas, scores greater than 4 is categorized as poor sleep quality. This has diagnostic sensitivity and specificity of $89.6 \%$ and $86.5 \%$ respectively. ${ }^{11,12}$

The third component, Epworth Sleeping Scale (ESS) assesses participants' daytime sleepiness. It consists of eight self-rated questions that measure subject's likelihood to fall asleep in various commonly encountered situations and produce a collective ESS score. Collective ESS score $>10$ translates to having as excessive daytime sleepiness. ESS has an internal consistency of 0.88 and test retest reliability of $0.92 .{ }^{13}$ Institutional Review Board of KEMU approved this study. An informed consent form was collected from all participants and confidentiality of information was ensured.

For data analysis, Statistical Package for Social Sciences (SPSS), version 20 (SPSS Inc., Chicago, Illinois, USA), was used. Qualitative data is presented as simple statistics or as percentages; quantitative data is presented as mean and standard deviation to provide meaningful information. The Chi-square test was used to compare the differences between students divided according to different academic scores. Post-hoc testing was done to evaluate the significance among different groups. A statistical level of significance was set at less than 0.05 .

\section{RESULTS}

Out of 850 students selected, 810 (95.29\%) students completely filled out the questionnaire. Among them, 564 (69.6\%) were females and 246 (30.4\%) were males. Overall, mean age in sample was $21.35 \pm 1.51$ years. A total of 530 (65.4\%) students were labelled as poor sleepers, while 400 (49.4\%) students experienced excessive daytime sleepiness. Of the total, 418 (51.6\%) were from MBBS and 392 (48.4\%) were from Allied Health Sciences (AHS). Among all, 124 (15.3\%) students were from Second year, 328 (40.5\%) Third year, 312 (38.5\%) Fourth year and 46 (5.7\%) from the Final year. More than half (54.1\%) were day scholars. Majority ( $85.1 \%$ ) belonged to urban areas. Study and sleep habits are shown in Table I.

Table I: Demographic distribution of population.

\begin{tabular}{|l|c|}
\hline & N (\%) \\
\hline Night sleep duration: & $10(1.2 \%)$ \\
$<4$ hours & $186(23 \%)$ \\
$4-6$ hours & $484(59.8 \%)$ \\
$7-10$ hours & $130(16 \%)$ \\
10 hours & \\
\hline Day time nap: & $454(56 \%)$ \\
Usually & $356(44 \%)$ \\
Rarely & \\
\hline Study hours (daily): & $232(28.6 \%)$ \\
$<2$ hours & $290(35.8 \%)$ \\
$2-4$ hours & $168(20.7 \%)$ \\
$4-6$ hours & $120(14.8 \%)$ \\
6 hours & \\
\hline
\end{tabular}

No significant relationship was found between PSQI and academic scores $\left(x^{2}=3.55, d f=4, p=0.47\right)$. However, academic scores had a strong association with ESS scores $\left(x^{2}=14.82, d f=4, p=0.005\right)$. Post-hoc testing demonstrate relationship of students securing more than $90 \%$ scores with ESS score ( $z: 3.4)$ but with small effect size $\left(v^{2}=0.135\right.$, Table II).

Significant association of PSQI was found with MBBS/AHS class $\left(x^{2}=7.48 d f=1, p=0.006\right)$, academic year $\left(x^{2}=9.33, d f=3, p=\right.$ $0.025)$, residence $\left(x^{2}=3.99, d f=1, p=0.046\right)$, night sleep duration $\left(x^{2}=14.46 \mathrm{df}=3, p=0.002\right)$ and day time nap $\left(x^{2}=22.81, d f=4\right.$, $\mathrm{p}=<.001)$. 
Table II: Association of PQSI \& ESS score with academic scores.

\begin{tabular}{|c|c|c|c|c|c|c|}
\hline & \multicolumn{5}{|c|}{ Academic scores } & \multirow[b]{2}{*}{ p-value } \\
\hline & $<60 \%$ & $60-70 \%$ & $70-80 \%$ & $80-90 \%$ & $>90 \%$ & \\
\hline $\begin{array}{l}\text { PSQI score } \\
\text { Normal } \\
\text { Poor }\end{array}$ & $\begin{array}{l}10(1.2 \%) \\
22(2.7 \%)\end{array}$ & $\begin{array}{c}90(11.1 \%) \\
202(24.9 \%)\end{array}$ & $\begin{array}{l}128(15.8 \%) \\
212(26.2 \%)\end{array}$ & $\begin{array}{l}42(5.2 \%) \\
74(9.1 \%)\end{array}$ & $\begin{array}{l}10(1.2 \%) \\
20(2.5 \%)\end{array}$ & 0.47 \\
\hline $\begin{array}{l}\text { ESS score } \\
\text { Normal sleep } \\
\text { Excessive daytime sleepiness }\end{array}$ & $\begin{array}{l}18(2.2 \%) \\
14(1.7 \%)\end{array}$ & $\begin{array}{l}158(19.5 \%) \\
134(16.5 \%)\end{array}$ & $\begin{array}{l}164(20.2 \%) \\
176(21.7 \%)\end{array}$ & $\begin{array}{l}64(7.9 \%) \\
52(6.4 \%)\end{array}$ & $\begin{array}{c}6(0.7 \%) \\
24(3.0 \%)\end{array}$ & 0.005 \\
\hline
\end{tabular}

Table III: Association of PQSI \& ESS score with different variables.

\begin{tabular}{|c|c|c|c|c|c|c|}
\hline & \multicolumn{3}{|c|}{ PSQI Score } & \multicolumn{3}{|c|}{ ESS Score } \\
\hline & Normal & Poor & p-value & Normal sleep & Excessive day time sleepiness & p-value \\
\hline $\begin{array}{l}\text { Class: } \\
\text { MBBS } \\
\text { AHS }\end{array}$ & $\begin{array}{c}126(15.6 \%) \\
154(19.01 \%)\end{array}$ & $\begin{array}{l}292(36.05 \%) \\
238(29.38 \%)\end{array}$ & 0.006 & $\begin{array}{l}216(26.67 \%) \\
194(23.95 \%)\end{array}$ & $\begin{array}{l}202(24.94 \%) \\
198(24.44 \%)\end{array}$ & 0.534 \\
\hline $\begin{array}{l}\text { Gender: } \\
\text { Female } \\
\text { Male }\end{array}$ & $\begin{array}{c}198(24.44 \%) \\
82(10.12 \%)\end{array}$ & $\begin{array}{l}366(45.19 \%) \\
164(20.25 \%)\end{array}$ & 0.626 & $\begin{array}{l}266(32.84 \%) \\
144(17.78 \%)\end{array}$ & $\begin{array}{l}298(36.79 \%) \\
102(12.59 \%)\end{array}$ & 0.003 \\
\hline $\begin{array}{l}\text { Academic year: } \\
2^{\text {nd }} \text { year } \\
3^{\text {rd }} \text { year } \\
4^{\text {th }} \text { year } \\
5^{\text {th }} \text { year }\end{array}$ & $\begin{array}{r}30(3.70 \%) \\
121(14.94 \%) \\
117(14.44 \%) \\
12(1.48 \%)\end{array}$ & $\left\{\begin{array}{c}94(11.60 \%) \\
207(25.56) \\
195(24.07 \%) \\
34(4.20 \%)\end{array}\right.$ & 0.025 & \begin{tabular}{|c|}
$68(8.40 \%)$ \\
$161(19.88 \%)$ \\
$169(20.86 \%)$ \\
$12(1.48 \%)$
\end{tabular} & $\begin{array}{c}56(6.91 \%) \\
167(20.62 \%) \\
143(17.65 \%) \\
34(4.20 \%)\end{array}$ & 0.003 \\
\hline $\begin{array}{l}\text { Residence: } \\
\text { Urban } \\
\text { Rural }\end{array}$ & $\begin{array}{c}250(30.86 \%) \\
30(3.70 \%)\end{array}$ & $\begin{array}{c}446(55.06 \%) \\
84(10.37 \%)\end{array}$ & 0.046 & $\begin{array}{c}354(43.70 \%) \\
56(6.91 \%)\end{array}$ & $\begin{array}{c}342(42.22 \%) \\
58(7.16 \%)\end{array}$ & 0.731 \\
\hline $\begin{array}{l}\text { Night sleep duration: } \\
<4 \text { hours } \\
4-6 \text { hours } \\
7-10 \text { hours } \\
10 \text { hours }\end{array}$ & $\begin{array}{c}48(5.93 \%) \\
184(22.72 \%) \\
48(5.93 \%) \\
0(0 \%)\end{array}$ & $\mid \begin{array}{c}82(10.12 \%) \\
300(37.04 \%) \\
138(17.04 \%) \\
10(1.23 \%)\end{array}$ & 0.002 & $\begin{array}{c}56(6.91 \%) \\
248(30.62 \%) \\
102(12.59 \%) \\
04(0.49 \%)\end{array}$ & $\begin{array}{c}74(9.14 \%) \\
236(29.14 \%) \\
84(10.37 \%) \\
06(0.74 \%)\end{array}$ & 0.186 \\
\hline $\begin{array}{l}\text { Day time nap: } \\
\text { Never } \\
\text { Almost never } \\
\text { Occasionally } \\
\text { Mostly } \\
\text { Always }\end{array}$ & $\begin{array}{c}42(5.19 \%) \\
34(4.20 \%) \\
100(12.35 \%) \\
74(9.14 \%) \\
30(3.70 \%)\end{array}$ & $\begin{array}{c}36(4.44 \%) \\
38(4.69 \%) \\
204(25.18 \%) \\
178(21.98 \%) \\
74(9.14 \%)\end{array}$ & $<0.001$ & $\begin{array}{c}54(6.67 \%) \\
46(5.68 \%) \\
176(21.73 \%) \\
100(12.35 \%) \\
34(4.20 \%)\end{array} \mid$ & $\begin{array}{c}24(2.96 \%) \\
26(3.21 \%) \\
128(15.80 \%) \\
152(18.77 \%) \\
70(8.64 \%)\end{array}$ & $<0.001$ \\
\hline
\end{tabular}

While significant association of ESS was found only with gender $\left(x^{2}=8.86, d f=1, p=0.003\right)$, academic year $\left(x^{2}=\right.$ $13.84 d f=3, p=0.003)$ and day time nap $\left(x^{2}=47.75, d f=4\right.$ $\mathrm{p}=<0.001$, Table III).

\section{DISCUSSION}

Scores from both of these scales (ESS and PSQI) show that the sleep quality of medical students is not good. Pakistani medical students exhibit unsatisfactory and unhealthy habits towards their sleep. Because of the excessive academic burden and pressure, they prefer not to sleep and allocate their sleep hours to study time. However, the results how that even if sleep does not affect the academic performance directly, daytime sleepiness caused due to lack of sleep can influence academic performance. A normal sleep cycle is definitely important not only as for general physical health but for sound mental health, as well.

To explore the significant relation between sleep and academic scores, data was collected from medical students of King Edward Medical University, including both MBBS and AHS students. The designed questionnaire consisted of demographic information and two validated tools, PSQI and ESS. The Pittsburgh Sleep Quality Index (PSQI) is an effective instrument used to measure the quality and patterns of sleep in adults, differentiating poor from good sleep quality by measuring different aspects of sleep disturbance during past month. ${ }^{11}$ The Epworth Sleepiness Scale (ESS) assesses participants' general level of daytime sleepiness in recent times. ${ }^{13}$

Majority of our population was female $(69.6 \%)$, which is quite high from other studies. ${ }^{1,2}$ This could possibly be due to the fact that admissions in medical colleges are being done on open merit and more women are getting admissions than men. ${ }^{14}$ Majority of our population had 7-10 hours of night sleep duration, with study hours of upto 4 hours per day. These observations were quite comparable with existing data. ${ }^{1}$ 
Having brief overview of results, there is a remarkable proportion of students with poor sleep quality. These findings were quite opposite to local data. ${ }^{1}$ Though Saharian et al. showed $57.4 \%$ population as poor sleepers, which is quite comparable to the present data. ${ }^{7}$ On stratification, difference between sleep quality of MBBS and AHS students turns out to be significant $(p=0.006)$. Results show that $34.61 \%$ of the students included in study had normal sleep quality according to PSQI scores; out of which, only $15.6 \%$ students were of MBBS group. However, of students having poor sleep, $29.38 \%$ (out of $65.43 \%$ ) students belonged to AHS group showing a greater prevalence of poor sleep in MBBS group. Similarly, academic year, residence, night sleep duration and day time nap had significant association with sleep quality in this study. Total hours slept, use of sleeping pills, presence of chronic physical illness, frequent use of alcohol were factors resulting in poor sleep quality; but not studied in our population. ${ }^{4,6}$

Our study showed that sleep quality does not affect academic performance. Similarly, cross- sectional survey reported no association between sleep and academic records. ${ }^{2}$ On the contrary, international data showed poor sleep quality association with low academic performance. ${ }^{15,16}$ Maheswari et al. reported 512 students data from medical university in Karachi, Pakistan, which showed that mean GPA of poor sleepers was significantly lower than that of good sleepers ( $p$ $<0.001$ ). ${ }^{17}$ Almost half of the present group showed excessive daytime sleepiness; while Shin et al. showed only $15.9 \%$ prevalence of excessive daytime sleepiness. ${ }^{18}$ Comparable prevalence were reported in literature also. ${ }^{19-21}$

Contrary to PSQI, ESS scores demonstrated strong association with academic scores. Prevalence rate of about 36\% $(19.5 \%+16.5 \%)$ students' scores $60-70 \%$ results. Among these, $19.5 \%$ are having normal ESS score and $16.5 \%$ depict excessive daytime sleepiness. Decreased nocturnal sleep time and late bedtimes during week days were also reported to result in excessive daytime sleepiness. ${ }^{21}$ Female gender, psychological distress and total sleep time were reported to have significant association with excessive daytime sleepiness. ${ }^{20,21}$ This study showed gender, academic year and day nap time as significant factors affecting excessive daytime sleepiness.

However, non-availability of sleep labs and; hence, no hospital evidence and record of sleep patterns of study groups could have biased the results. The self-reporting of sleep patterns and exam scores by students themselves were possible sources of biases in this study.

\section{CONCLUSION}

Many factors may influence sleep in an enhancive or reductive manner. Students should maintain balance between the sleep and the study. Although there was no association of PSQI with academic performance in this study; however, ESS scores demonstrated significant impact on academic perfor- mance of these students.

\section{ETHICAL APPROVAL:}

The study protocol was designed in accordance with the ethical guidelines of the 1961 Declaration of Helsinki and approved by the Institutional Review Board of King Edward Medical University (KEMU), Lahore.

\section{PATIENTS' CONSENT:}

Not applicable.

\section{CONFLICT OF INTEREST:}

Authors declared no conflict of interest.

\section{AUTHORS' CONTRIBUTION:}

$\mathrm{RJ}$ : Contributed to the conception or design of the work; acquisition, analysis, and interpretation of data for the work. AUM: Drafted the work and revised it critically for important intellectual content.

MZS: Agreed to be accountable for all aspects of the work in ensuring that questions related to the accuracy or integrity of any part of the work are appropriately investigated and resolved.

SAN: Gave final approval of the version to be published.

\section{REFERENCES}

1. Surani AA, Zahid S, Surani A, Ali S, Mubeen M, Khan RH. Sleep quality among medical students of Karachi, Pakistan. J Pak Med Assoc 2015; 65(4):380-2.

2. Kazim M, Abrar A. Sleep patterns and academic performance in students of a medical college in pakistan. KUST Med J 2011; 3(2): p57-60.

3. Aabid A, Muhammad Bilal M, Kanwal S, Amanda B, Mulazim Hussain B. Effects of different sleeping patterns on academic performance in medical school students. Nat Sci 2013; 5(11): 1193-8. doi:10.4236/ns.2013.511146.

4. Nojomi M, Ghalhe Bandi MF, Kaffashi S. Sleep pattern in medical students and residents. Arch Iran Med 2009; 12(6):542-9.

5. Ford DE, Kamerow DB. Epidemiologic study of sleep disturbances and psychiatric disorders. An opportunity for prevention? JAMA 1989; 262(11):1479-84. doi: 10.1001/ jama.262.11.1479.

6. James BO, Omoaregba JO, Igberase OO. Prevalence and correlates of poor sleep quality among medical students at a Nigerian university. Anna Nigerian Med 2011; 5(1):1-5. doi: 10.4103/0331-3131.84218.

7. Sahraeian A, Javadpour A. Sleep disruption and its correlation to psychological distress among medical students. Shiraz E-Med J 2010; 11(1):12-7.

8. Lowry M, Dean K, Manders K. The link between sleep quantity and academic performance for the college student. Sentience 2010; 3(2):16-9.

9. Singh R, Undevia NS, Schuman C, Attarian H. Excessive daytime sleepiness among attending physicians: A pilot survey study at an academic institution. Sleep Med 2011; 12(8):808-10. doi: 10.1016/j.sleep.2011.04.003. 
10. Medeiros ALD, Mendes DB, Lima PF, Araujo JF. The relationships between sleep-wake cycle and academic performance in medical students. Biol Rhythm Res 2001; 32(2):263-70. doi.org/10.1076/brhm.32.2.263.1359.

11. Buysse DJ, Reynolds CF, Monk TH, Berman SR, Kupfer DJ. The Pittsburgh Sleep Quality Index: A new instrument for psychiatric practice and research. Psychiatry Res 1989; 28(2):193-213. doi: 10.1016/0165-1781(89)90047-4.

12. Buysse DJ, Reynolds III CF, Monk TH, Hoch CC, Yeager AL, Kupfer DJ. Quantification of subjective sleep quality in healthy elderly men and women using the pittsburgh sleep quality index (PSQI). Sleep 1991; 14(4):331-8.

13. Johns MW. Reliability and factor analysis of the Epworth Sleepiness Scale. Sleep 1992; 15(4):376-81. doi: 10.1093/ sleep/15.4.376.

14. Shaikh MA, Ikram S, Zaheer R. Influences on medical career choice and future medical practice plans among women: Perspective from final year students and house officers. J Pak Med Assoc 2018; 68(2):272-5.

15. Gilbert SP, Weaver CC. Sleep quality and academic performance in university students: A wake-up call for college psychologists. J Coll Student Psychother 2010; 24(4):295-306. doi.org/10.1080/87568225.2010.509245.

16. Ahrberg K, Dresler M, Niedermaier S, Steiger A, Genzel L.
The interaction between sleep quality and academic performance. J Psychiatric Res 2012; 46(12):1618-22. doi: 10.1016/j.jpsychires.2012.09.008.

17. Maheshwari G, Shaukat F. Impact of poor sleep quality on the academic performance of medical students. Cureus 2019; 11(4):e4357. doi: 10.7759/cureus.4357.

18. Shin C, Kim J, Lee S, Ahn Y, Joo S. Sleep habits, excessive daytime sleepiness and school performance in high school students. Psychiatry Clin Neurosci 2003; 57(4):451-3. doi: 10.1046/j.1440-1819.2003.01146.x.

19. Rodrigues RND, Viegas CA, Abreu e Silva AA, Tavares P. Daytime sleepiness and academic performance in medical students. Arquivos de Neuro-psiquiatria 2002; 60(1):6-11. doi: 10.1590/s0004-282x2002000100002.

20. Naeem A, Kiblawi MA, Ahmad E, Samad SBA, Samad AA, Naeem $A$, et al. Comparison of daytime sleepiness in medical university students using epworth sleepiness scale (ESS). PSBR 2014; 2(2):58-62. doi:10.12966/psbr. 06.06.2014.

21. El Hangouche AJ, Jniene A, Aboudrar S, Errguig L, Rkain H, Cherti $\mathrm{M}$, et al. Relationship between poor quality sleep, excessive daytime sleepiness and low academic performance in medical students. Adv Med Edu Prac 2018; 9:631-8. doi: 10.2147/AMEP.S162350. 